\title{
Mismatch between Anthropometric Body Dimensions and Classroom Furniture in Malaysian Universities
}

\author{
Negin Ozve Aminian* and Fairuz I. Romli \\ Department of Aerospace Engineering, University Putra Malaysia \\ *Negin_oa@yahoo.com
}

\begin{abstract}
The main objective of study is to highlight possible mismatch between the student's body dimensions and the dimensions of classroom furniture used in most Malaysian universities. This issue is pertinent due to the notable increase in the number of international students who are enrolled in Malaysian universities each year. The matching of body dimensions and classroom furniture is vital to promote proper sitting posture. Body dimensions of the people from the few different countries that are perceived to make up the current student's population in Malaysia are measured against dimensions of prevalent chairs and desks used in the classroom. The sample case study is done in Faculty of Engineering, Universiti Putra Malaysia but it is believed that the derived conclusion can also be extended to other universities in Malaysia. All in all, several mismatches have been found and highlighted for a better planning and design of classroom furniture.
\end{abstract}

Keywords: classroom furniture, Malaysian universities, body dimensions

\section{INTRODUCTION}

Students spend at least several hours a day at university campus and most of the time they are working in a sitting position in their classroom. Many tasks are done a seated position - using laptop, writing and reading are several examples of task that are performed daily by students in class. Considering the amount time they spend sitting in the classroom, it is important to have suitable furniture that appropriately supports their body in performing those tasks. Otherwise, they may suffer fatigue and back pain for sitting in an uncomfortable position for a long period of time. In addition, proper design of classroom furniture reduces muscular disorder and greatly helps to increase student's concentration during their lectures or study.

Ergonomic design of chairs in classroom is closely tied to anthropometric features of the students' population. It is believed that there is a growing mismatch between design feature of the furniture used in the classroom in many Malaysian universities and the anthropometric features of the students. Part of this problem can be contributed to the growing population of international students in Malaysian universities. It is clear that Malaysian or Asian students can have very different anthropometric features or body dimensions compared to their international counterparts who might come from European or African countries.

To support this notion, a preliminary survey was done on 500 students from five different universities: Universiti Putra Malaysia (UPM), Universiti Kebangsaan Malaysia (UKM), Universiti Tenaga Nasional (UNITEN), Lim Kok Wing University and Universiti Malaya (UM). Students through the survey were asked if the dimensions of the current chair such as height is suitable for them based on their experiences in the classroom of their universities. The students were selected from different nationalities to represent the diverse background of the current student population in Malaysian universities nowadays. Summary of the participants' background in terms of their gender and nationality is shown in Fig. 1 and Fig. 2, respectively.

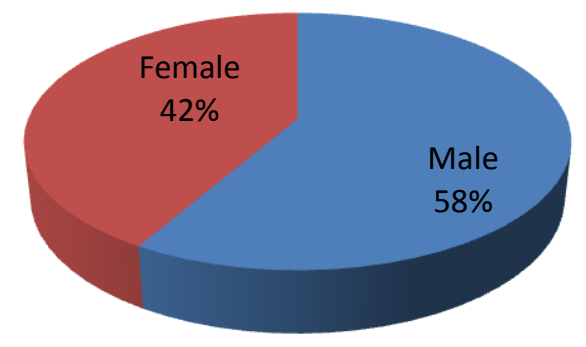

Fig. 1: Gender distribution of survey participants

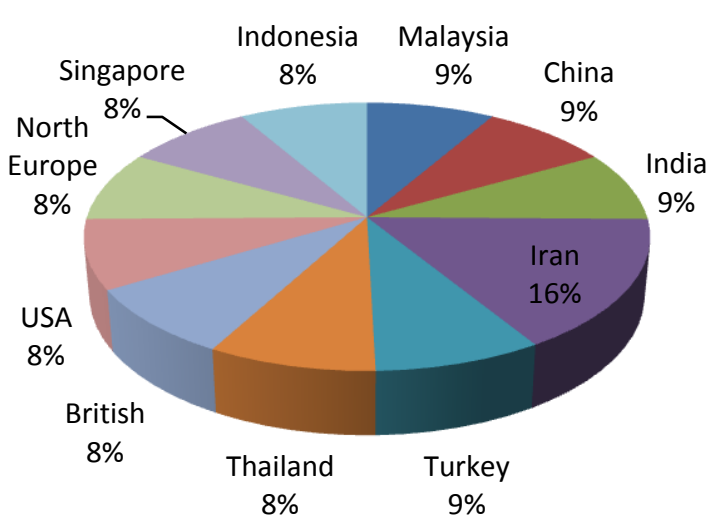

Fig. 2: Nationality distribution of survey participants 
It is concluded form the survey that most of the students were not happy with current chairs in their classroom. Some of the issues pointed out by them highlight design deficiencies of currents furniture used. This survey result provides the necessary support to the notion that there are ongoing problems with design of chairs used in current classroom in many Malaysian universities and this is the solid background to future pursue this study.

\section{ERGONOMIC PRINCIPLE OF CHAIR DESIGN}

One of the main health issues in workplace is back pain, which leads to high medical costs and loss of efficiency in the work position. This is also true for students who are studying in their classroom furniture settings. According to physicians and researchers, they believe this common low back pain in not a disease. Based on the fundamental principles of seat design, it should not only support the spine but also the lumbar spine. The lumbar support in seat design will maintain the S-curve shape of the spine in sitting posture as in the case when we are in our standing posture. A proper seating posture should be comfortable and permit user's feet on the floor. Furthermore, it should not subject to much stress on the user's buttock back and /or arm.

In general, anthropometric data of the users can assist the designers in finding if there is a mismatch between their body dimensions and the design of the consumer products in order to reduce any discomfort that such situation may cause to users. As highlighted in Figure 3, static human physical characteristics data is usually measured with the subject in a seated and erect posture, with 90 degrees knee bent. The required human body dimensions to assess the design of a chair include 1.Stature, 2.Shoulder height, 3.Elbow height, 4.Sitting eye height, 5. Thigh thickness, 6. Abdominal depth,7 .Buttock-popliteal length 8. Hip breadth, 9.Popliteal height, 10. Forearm.

In classroom setting, minimum and maximum shoulder angles for students while writing as being recommended by many ergonomists is $0-25^{\circ}$ for shoulder flexion and $0^{\circ}$ $20^{\circ}$ is for shoulder abduction. The corresponding cosines are $1\left(0^{\circ}\right)$ and $0.9063\left(25^{\circ}\right)$ for flexion angles and the corresponding cosines are $1\left(0^{\circ}\right)$ and $0.9397\left(20^{\circ}\right)$ for abduction angles. Minimum and maximum desk height is determined by the following equations .

- $\quad$ Minimum desk height $=$ seat height $+\mathrm{hE}$

where $\mathrm{hE}=\mathrm{hEV}+\mathrm{U}[(1-1)+1(1-1)]=\mathrm{hEV}$

- $\quad$ Maximum desk height $=$ seat height $+\mathrm{hE}$

where: $\mathrm{hE}=\mathrm{hEv}+\mathrm{U}\left[\left(1_{-} \cos \theta\right)+\cos \theta\left(1_{-} \cos \beta\right)\right]$

$\mathrm{hEv}+\mathrm{U}\left[\left(1 \_0.9063\right)+0.9603\left(1_{-} \quad 0.9397\right)\right]$

$0.8517 \mathrm{hEv} \overline{+} 0.1483 \mathrm{Hs}$, since $\overline{\mathrm{U}}=\mathrm{hS}-\mathrm{hEv}$
When the height of the desk is shorter than the minimum desk height or higher than the maximum desk height, it is defined as mismatch of elbow-shoulder height and desk height.
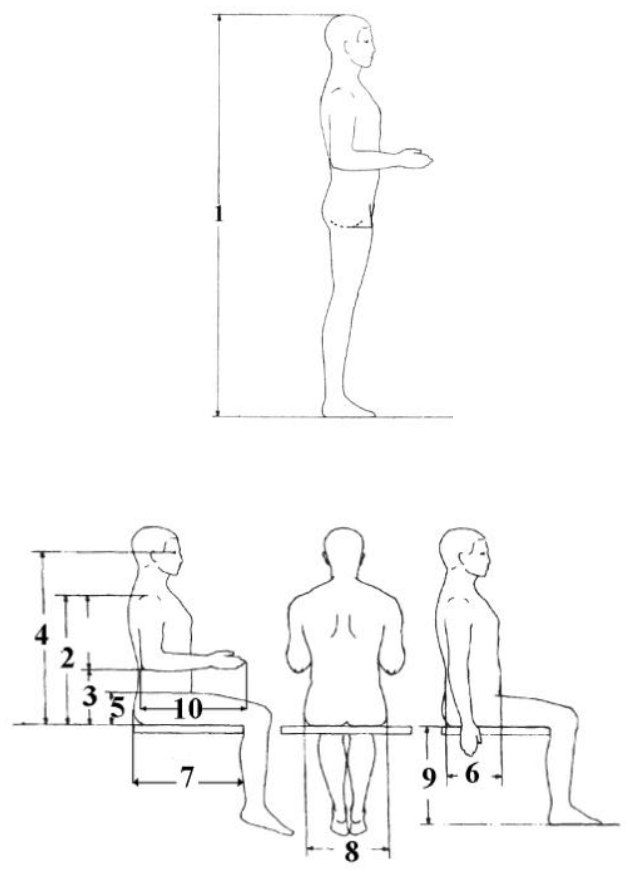

Fig. 3: Measurement of static human physical criteria Jurgens,H.w.;Matzdorff.I.;Windberg,J,International Anthropomeric Data for Work-Place and Machinary Design, 1998 ISSN-0720-1869

\section{CASE STUDY}

To study whether there is a current mismatch between the classroom furniture in most universities in Malaysia and the students' body dimensions, an example case study is done by examining the classroom facilities in Faculty of Engineering, Universiti Putra Malaysia.

\section{Methodology}

The summary of steps taken in the execution of this case study is shown in Figure 4. First, physical anthropometric data to represent the different nationalities of the student population is searched in the public literatures. Next, all the required data and parameters for the comparison are identified. Related standards and relationships about the design ergonomics are studied and become the basis for the comparison. Dimensions of current furniture available in the classroom are then measured and the corresponding values of anthropometric features to represent the student population are analyzed and extracted from the reference published data. After that, the comparison between the furniture dimensions and representative anthropometric 
data is done. Based on the results of the comparison, any existing mismatches can be identified.

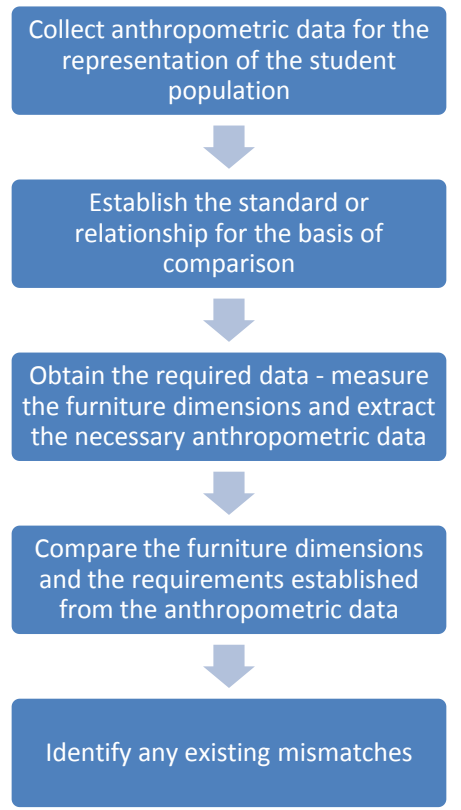

Fig. 4: Flowchart of the methodology

\section{Results of Case Study}

Table 1 summarizes the anthropometric data obtained to represent current students' population within the Faculty of Engineering, University Putra Malaysia.

Table 1: Anthropometric data for the students

\begin{tabular}{|l|l|l|l|l|l|}
\hline Female & $\mathrm{N}$ & StDev & Mean & Mode & Median \\
\hline WEIGHT & 170 & 9.967 & 0.764 & 50 & 52.000 \\
\hline HEIGHT & 170 & 6.27 & 159.29 & 160 & 159.00 \\
\hline
\end{tabular}

\begin{tabular}{|l|l|l|l|l|l|}
\hline Male & N & StDev & Mean & Mode & Median \\
\hline WEIGHT & 170 & 14.46 & 70 & 50 & 68.00 \\
\hline HEIGHT & 170 & 14.46 & 180 & 160 & 173.00 \\
\hline
\end{tabular}

Meanwhile measurements of the chair and desk available in the classroom of the Faculty of Engineering, Universiti Putra Malaysia are depicted in Fig. 5, Fig. 6 and Fig. 7.

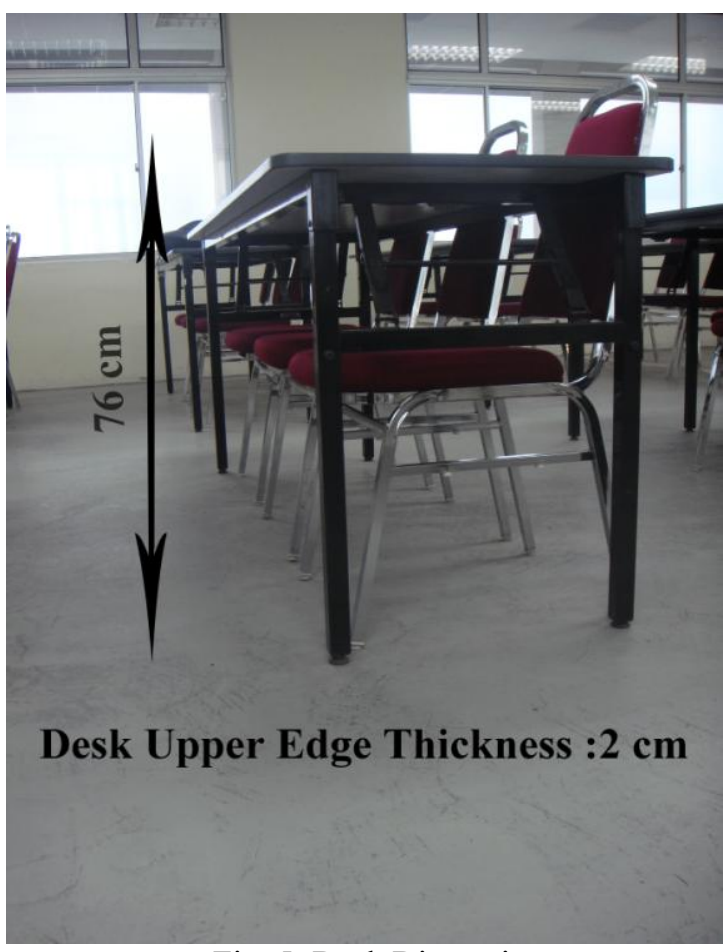

Fig. 5: Desk Dimensions

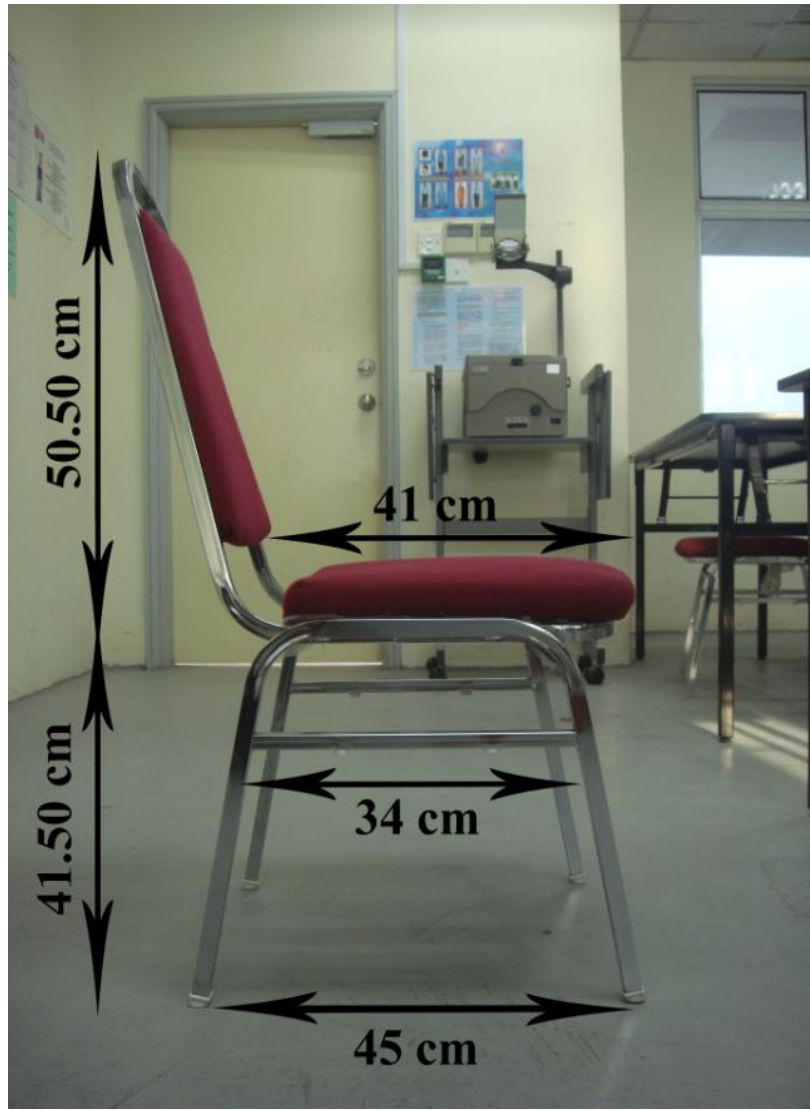

Figure 6: Dimensions of chair (side view) 


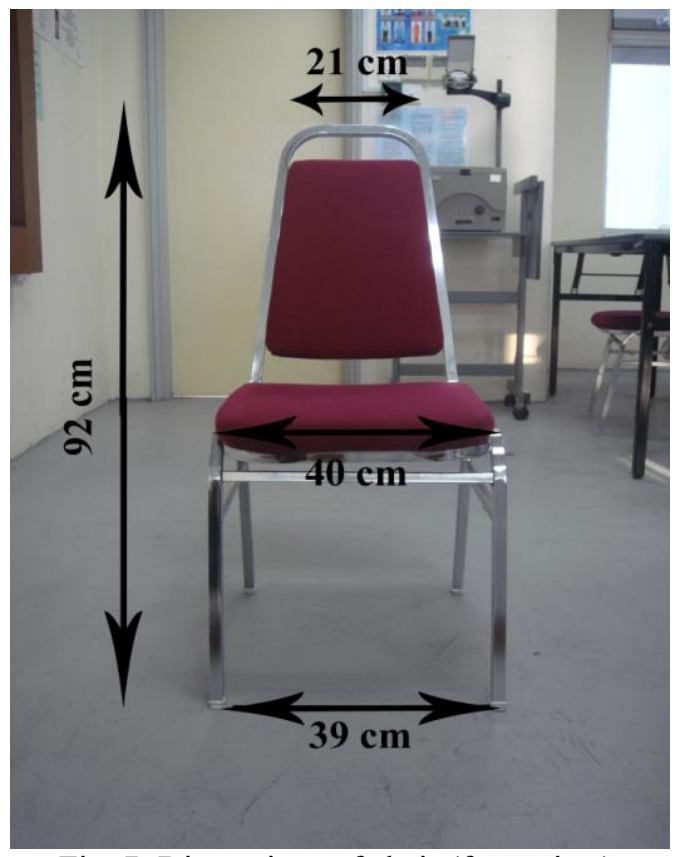

Fig. 7: Dimensions of chair (front view)

All in all, comparison between students' anthropometric data and design dimensions of the classroom furniture is summarized in Table 2. It can be observed that there exist several mismatches based on the ergonomics standard for furniture design.

Table 2: Table of comparison

\begin{tabular}{|c|c|c|c|}
\hline $\begin{array}{c}\text { Chair } \\
\text { Requirements }\end{array}$ & $\begin{array}{c}\text { Anthropometric } \\
\text { Measurement }\end{array}$ & $\begin{array}{c}\text { Chair } \\
\text { Dimensions }\end{array}$ & $\begin{array}{c}\text { Body } \\
\text { Dimensions }\end{array}$ \\
\hline Seat height & $\begin{array}{c}\text { Popliteal } \\
\text { Height+ Shoe } \\
\text { Measure }\end{array}$ & 41.50 & 38 \\
\hline Seat Depth & $\begin{array}{l}\text { Buttock popliteal } \\
\text { Length_- } \\
\text { Clearance } \\
\text { Measure }\end{array}$ & 41 & 42 \\
\hline Seat Width & $\begin{array}{l}\text { Hip Breadth in } \\
\text { sitting posture+ } \\
\text { Cloth Measure }\end{array}$ & 40 & 41.26 \\
\hline Seat pan angle & -------- & 0.8 & 0.5 \\
\hline $\begin{array}{l}\text { Backrest } \\
\text { height }\end{array}$ & -------- & 50.50 & 49.08 \\
\hline Desk Height & $\begin{array}{c}\text { Seat } \\
\text { height }+ \text { elbow } \\
\text { height }\end{array}$ & 76 & $38+28=66$ \\
\hline
\end{tabular}

In order to remedy this situation, suggestions on the new dimensions are as follows:

- Chair seat depth is 41 and it should be 42 according to new anthropometric dimensions

- Seat width and hip breadth mismatch: the current seat width is 40 and it should be changed to $41.26 \mathrm{~cm}$

- Desk height and elbow height mismatch from sitting surface: The real height of desk used in university is
76 and we mines $41.5 \mathrm{~cm}$ as the seat height to find the desk height from sitting surface. The amount is 34.5

- According to formulas for minimum and maximum chair height I obtained 17.73 and 25 respectively. It is recognized that $9.5 \mathrm{~cm}$ is mismatch

- Backrest height and shoulder height mismatch: Based on the ergonomists it should be adopted with $95^{\text {th }}$ shoulder height of male and is 64.08 in my survey. However, the backrest of current educational chair in university of Putra is $92 \mathrm{~cm}$. There is $28 \mathrm{~cm}$ mismatch.

- Gap between backrest and desk: It should be measured based on the average of $5^{\text {th }}$ percentile of female to $95^{\text {th }}$ percentile of male abdominal depth. In my data I obtained it $28 \mathrm{~cm}$. As we can see this gap is different in classroom decoration for individuals and the desk is too heavy to move and not easy to adjust the height of desks for per students based on his/her own body dimensions to be more comfortable when writing or working with laptops.

\section{CONCLUSION}

Data obtained from anthropometric dimensions indicates that there are a lot of differences even between people of the same race and nationality differences who make up the population of students in universities across Malaysia. The purpose of this study is to find the mismatch between the anthropometric dimensions and the current furniture used in classrooms of universities in Malaysia. Faculty of Engineering, Universiti Putra Malaysia is selected as the sample case study. From the comparison result, several mismatches are found and this leads to the conclusion that the design of furniture used in the classroom needs to be improved to better accommodate the studying process of the students. The scenario can also be extended to other universities in Malaysia.

\section{Acknowledgements}

I like to thank Dr. Rizal Zahari for his recommendations and suggestions have been invaluable for the project. I also wish to extend my thanks to Professor Alan Hedge at Cornell University, USA for his assistance. Finally, my thanks go to all students of UPM and other universities in Malaysia who have participated in this study.

\section{References}

1. C.G. Drury and B.G. Coury. A methodology for chair evaluation. Applied Ergonomics 1982, 13.3, 195-202 .Department of Industrial Engineering, State University of New York at Buffalo, USA.

2-Claudia Parcells, M.S.N., R.N., Manfred Stommel, Robert P. Hubbard, Mismatch of Classroom Furniture and 
Student Body Dimensions, JOURNAL OF ADOLESCENT HEALTH Vol. 24, No. 4

3- Scott Openshaw, Erin Taylor, Ergonomics and Design A Reference Guide ,Allsteel,2006

4-. K. Karmegam, S. M. Sapuan, M. Y. Ismail, N. Ismail1, M. T. Shamsul Bahri, S. Shuib, G.K. Mohana, P. Seetha, P. TamilMoli and M. J. Hanapi. Anthropometric study among adults of different ethnicity in Malaysia. Universiti Putra Malaysia. 2011

5. M. A. Mououdi, Static anthropometric characteristics of Tehran University students age 20-30, School of Heahh, Mazandaran University of Medical Sciences, I. R. Iran

.1997

6. Seyyed Jalil Mirmohammadi, Amir Houshang Mehrparvar, Somayyeh Jafari, and Mehrda Mostaghaci , An Assessment of the Anthropometric Data of Iranian University Students ,Department of Occupational Medicine, Shahid Sadoughi University of Medical Sciences, Yazd, Iran.2011

7. Ali_Is eri, Nurullah Arslan Estimated anthropometric measurements of Turkish adults and effects of age and geographical regions, Fatih University, Turkey, 2009

8. Jaruwan Klamklay, Angoon Sungkhapong, Nantakrit Yodpijit, Patrick E. Patterson, Anthropometry of the southern Thai population, Institute of Technology, Thailand, 2007

9- Ahlstrom, V., \& Longo, K. (2003). Human Factors Design Standard (HF-STD-001). Atlantic City International Airport, chapter 14

10-Claudia Parcells, M.S.N., R.N., Manfred Stommel, Robert P. Hubbard, Mismatch of Classroom Furniture and Student Body Dimensions, JOURNAL OF ADOLESCENT HEALTH Vol. 24, No. 4 